\title{
O Agente de Desenvolvimento como Protagonista da Mudança Local - A Lei Geral das Micro e Pequenas Empresas em Mato Grosso do Sul
}

L'agent de le développement comme protagoniste du modification locale - La loi générale de micro et petites entreprises dans le Mato Grosso do Sul

\section{The agent of development as a local change protagonist - The general law of micro and small companies in Mato Grosso do Sul}

\author{
El agente de desarrollo local como un protagonista del cambio local - La ley genereal de micro \\ y pequeñas empresas en Mato grosso do sul
}

Isabella Carvalho Fernandes*

(isabellacarvalhofernandes@gmail.com)

Recebido em 1이일 2013; revisado e aprovado em 22/06/2013; aceito em 10/11/2013

\begin{abstract}
Resumo: s Agentes de Desenvolvimento são peças fundamentais no trabalho de implementação da Lei Geral das Microempresas e Empresas de Pequeno Porte, e representam o principal agregador de forças entre o Poder Público, lideranças empresariais e da sociedade. No Estado de Mato Grosso do Sul atualmente são 57 agentes nomeados que trabalham em prol do desenvolvimento dos pequenos negócios urbanos e rurais. Esses Agentes tem como papel principal a implementação da Lei, mas o seu trabalho ultrapassa essas atividades, desempenhando função essencial na coordenação e continuidade do processo de desenvolvimento sustentável dos Municípios.

Palavras-chave: Agente de Desenvolvimento. Lei Geral. Desenvolvimento Sustentável.

Abstract: The development agents are fundamental tool in the work of implementing the general law of micro and small enterprises, and they represent the main deliverers of the public system, private leaderships and society outputs. In the state of Mato Grosso do Sul, now they are 57 nominated agents working pro the development of the small urban and rural businesses. These agents have as their main role the implementation of the Law, but their work surpasses these activities, playing a essential role of coordination and continuity of the process of the sustainable development of the municipalities.
\end{abstract}

Key words: Agents of Development. General Law. Sustainable development.

Resumen: Los agentes de desarrollo son piezas fundamentales a el trabajo de implementación de la Ley General do Micro y Pequeñas Empresas, y representan el principal agregador de fuerzas entre el poder público, líderes empresariales y la sociedad. En el estado de Mato Grosso do Sul ya son 57 agentes nominados que trabajan por el desarrollo de los pequeños negocios urbanos y rurales. Eses agentes tienen como principal rol la implementación de la Ley, pero su trabajo traspasa esa actividad, desarrollando un rol de coordinación y continuidad del proceso de desarrollo sostenible de los municipios.

Palabras clave: Agentes de desarrollo. Ley general. Desarrollo sostenible.

Resumé: Agents de développement jouent un rôle fondamental dans le travail de mise en œuvre de la loi générale de micro et petites entreprises, et représentent le principal agrégateur d'énergie entre le gouvernement, les dirigeants d'entreprises et de la société. Dans l'Etat du Mato Grosso do Sul sont actuellement 57 agents désignés qui travaillent pour le développement des petites entreprises des zones urbaines et rurales. Ces agents ont le rôle principal d'appliquer la loi, mais leur travail va au-delà de ces activités, en jouant le rôle clé dans la coordination et la continuité du processus de développement durable des municipalités.

Mots-clés: Agent de développement. Le droit général. Le développement durable.

\section{Introdução}

A atuação de atores locais é peça fundamental aos projetos de desenvolvimento territorial que almejam sucesso. Com este enfoque a definição dos Agentes de Desenvolvimento garante não só a implantação como também a sustentabilidade das ações realizadas nos municípios de Mato Grosso do Sul.

O Agente de Desenvolvimento é o articulador e mobilizador dos esforços locais em prol do desenvolvimento. Esta necessidade de tornar a ação de desenvolvimento em atuação local que levou a inclusão da figura do Agente de Desenvolvimento na Lei Complementar 128/2008, que aprimorava a Lei Complemen$\operatorname{tar} 123 / 2006$, Lei Geral das Micro e Pequenas Empresas.

A Lei Geral das Microempresas e Empresas de Pequeno Porte nasceu com objetivo de promover o desenvolvimento local através do tratamento diferenciado e favorecido aos

\footnotetext{
“Serviço de Apoio às Micro e Pequenas Empresas de Mato Grosso do Sul (SEBRAE/MS), Campo Grande, MS, Brasil.
} 
pequenos negócios instalados nas diversas regiões de nosso país. Passado dois anos de sua criação, quando da necessidade de revisões que incluíssem benefícios aos negócios de pequeno porte, tal como a criação do Micro Empreendedor Individual, percebeu-se a necessidade de mobilizações locais que estimulassem a efetivação da Lei em ações públicas ou comunitárias realizadas localmente. Este motivo levou a inclusão de um capítulo que tratasse da nomeação do Agente de Desenvolvimento.

Este Agente que deveria estar fortemente envolvido com o meio empresarial e também com o setor público deveria influenciar as atividades relativas a implantação da Lei Geral, e ir além, coordenando e garantindo a continuidade de atividades voltadas ao desenvolvimento sustentável do município.

No Mato Grosso do Sul, atualmente são 57 Agentes de Desenvolvimento nomeados que trabalham pelo crescimento da economia municipal através do apoio aos negócios urbanos e rurais. Esses Agentes são responsáveis pela Implementação da Lei Geral que hoje alcança 26 municípios, e por levantar a bandeira do empreendedorismo como alternativa para inclusão social e geração de renda.

Este trabalho intenciona apresentar além dos conceitos e histórico quanto a Lei Geral e o trabalho dos Agentes de Desenvolvimento, relações entre o trabalho desses personagens e a promoção do desenvolvimento por meio da Lei Geral nos municípios de Mato Grosso do Sul.

\section{A Lei Geral das Microempresas e Empre- sas de Pequeno Porte como ferramenta de Desenvolvimento}

Instituída em 14 de dezembro de 2006, o objetivo da Lei Geral das Microempresas e Empresas de Pequeno Porte era regulamentar o que já estava disposto na Constituição Federal conferindo tratamento favorecido às Microempresas e Empresas de Pequeno Porte.

A concepção da Lei passou pela sociedade civil, entidades empresariais, poder legislativo, e poder executivo. Através da Lei Geral, foi instituído o regime tributário específico para o segmento, com redução da carga de impostos e simplificação dos processos de cálculo e recolhimento, que é o Simples
Nacional (LEI GERAL, 2013).

A Lei Geral já passou por quatro alterações (Leis Complementares 127/2007, $128 / 2008,133 / 2009$ e $139 / 2011$ ) todas com objetivo de aprimorar os benefícios concedidos aos pequenos negócios, refinando a estratégia de apoio a competitividade com foco na geração de emprego, distribuição de renda, inclusão social, na redução da informalidade objetivando o fortalecimento da economia.

Um dos aspectos importantes da Lei é a definição de Microempresa e Empresa de Pequeno Porte. Segundo a Lei Complementar consideram-se Micro Empresas aquelas que obtiverem faturamento anual até $\mathrm{R} \$$ 360.000,00 (trezentos e sessenta mil reais) e Empresas de Pequeno Porte aquelas que apresentarem faturamento anual entre $\mathrm{R} \$$ $360.000,00$ (trezentos e sessenta mil reais) e R \$ 3.600.000,00 (três milhões e seiscentos mil reais), conforme disposto no artigo $3^{\circ}$ da referida Lei:

Art. $3^{\circ}$ Para os efeitos desta Lei Complementar, consideram-se microempresas ou empresas de pequeno porte a sociedade empresária, a sociedade simples, a empresa individual de responsabilidade limitada e o empresário a que se refere o art. 966 da Lei $\mathrm{n}^{\circ}$ 10.406, de 10 de janeiro de 2002 (Código Civil), devidamente registrados no Registro de Empresas Mercantis ou no Registro Civil de Pessoas Jurídicas, conforme o caso, desde que:

I - no caso da microempresa, aufira, em cada ano-calendário, receita bruta igual ou inferior a $\mathrm{R} \$ 360.000,00$ (trezentos e sessenta mil reais); e

II - no caso da empresa de pequeno porte, aufira, em cada ano-calendário, receita bruta superior a $\mathrm{R} \$ 360.000,00$ (trezentos e sessenta mil reais) e igual ou inferior a $R \$$ 3.600.000,00 (três milhões e seiscentos mil reais). (Lei Complementar 139/2011).

A Lei Complementar 128 de 19 de dezembro de 2008, que altera a Lei Complemen$\operatorname{tar} 123 / 2006$, cria a figura do Micro Empreendedor Individual (MEI). Com faturamento inferior a $\mathrm{R} \$ 36.000,00$ (trinta e seis mil reais), após três anos a Lei Complementar 139 de 10 de novembro de 2011 altera os limites de faturamento do MEI para R\$ 60.000,00 (sessenta mil reais). A Lei representa uma chance para que pessoas que exercem atividades informais possam trabalhar na formalidade 
tendo acesso a crédito e aos serviços previdenciários. A tendência pelo empreendedorismo é motivada pela Lei, que dá condições para a formalização das atividades ou o início de uma atividade potencial sem que o empreendedor necessite desembolsar um investimento muitas vezes incompatível com seus recursos financeiros momentâneos.

O Micro Empreendedor Individual possui registro no Cadastro Nacional de Pessoas Jurídicas e apesar de seu baixo faturamento é uma unidade empresarial que apesar de estar desobrigado de contabilidade formal, exige do empresário organização e gestão de seu negócio. $\mathrm{O}$ empreendedor formalizado pode empregar uma pessoa, e passa a ter possibilidade de venda ao Governo e a outras empresas, aumentando seu acesso ao mercado (LEI GERAL, 2013).

Mais que uma política governamental de assistência ao trabalhador autônomo, o Micro Empreendedor Individual pode fazer com que essas pessoas prosperem em suas atividades empresariais. $\mathrm{O}$ acesso ao mercado e as novas possibilidades, conduzidas em uma gestão adequada, e com a definição da missão e objetivos da empresa, pode fazer com que esse empreendedor prospere tornando-se um proprietário de Micro Empresa.

A Lei Geral prevê ainda benefícios para as pequenas empresas em diversos aspectos usuais nos pequenos negócios, como a simplificação e desburocratização, as facilidades no acesso ao mercado, ao crédito e a justiça, o estímulo à inovação e à exportação.

Quanto a simplificação a Lei instituiu o regime especial e unificado de arrecadação de tributos e contribuições, o Simples Nacional. O Regime é administrado pelo Comitê Gestor (CGSN) composto por representantes da Secretaria da Receita Federal, Estados e do Distrito Federal, e dos Municípios. O Simples Nacional abrange os tributos: IRPJ, CSLL, PIS/PASEP, CONFINS, IPI, ICMS, ISS e a Contribuição para a Seguridade Social Patronal (LEI GERAL, 2013).

A desburocratização ocorre através da facilitação nos procedimentos de inscrição, alteração e baixa de empresas. No caso do Micro Empreendedor Individual o procedimento pode ser realizado através do Portal do Empreendedor, sem custos.

O acesso a mercado é possível através das compras da administração pública. Entre os benefícios previstos está a possibilidade de apresentar documentos comprobatórios de regularidade fiscal apenas no ato da contratação, tendo prazo para sanar restrições existentes. A possibilidade de empate ficto quando a Microempresa poderá ser convidada a apresentar nova proposta inferior a apresentada por uma empresa de grande porte, após análise da margem de preferência. Outros aspectos podem estar contemplados já no edital de licitação, como o certame exclusivo para Microempresas e Empresas de Pequeno Porte em até 80 mil reais, ou a obrigação de subcontratação ou contratação em cotas de um pequeno empreendimento pela grande empresa vencedora da licitação (LEI GERAL, 2013).

A Lei Geral facilita ainda a obtenção de empréstimos e reduz os custos de financiamentos para as microempresas e empresas de pequeno porte; Prevê a realização de incentivos para investimentos em tecnologia com a alocação de um mínimo de $20 \%$ dos recursos federais, estaduais e municipais aplicados em pesquisa, desenvolvimento e capacitação tecnológica por parte de instituições públicas de fomento à tecnologia; Estimula a utilização, pelas micro e pequenas empresas, de formas alternativas para o tratamento de seus conflitos, como os institutos de conciliação prévia, mediação e arbitragem; E estabelece que a fiscalização, no que se refere aos aspectos trabalhista, metrológico, sanitário, ambiental e de segurança das microempresas e das empresas de pequeno porte deve ter natureza orientadora, exceto nos casos em que a atividade da empresa fiscalizada for considerada como de alto risco (LEI GERAL, 2013).

O SEBRAE Nacional, em um esforço para que todos os benefícios previsto na Lei Geral chegassem aos pequenos empreendimentos instalados nos municípios, desenvolveu o Indicador de Implementação da Lei Geral, onde através de um questionário de 58 perguntas que devem ser acompanhadas de evidências práticas, mensura a aplicação da Lei nos municípios considerando os quesitos Uso do Poder de Compras (Acesso a Mercados), Micro Empreendedor Individual, Desburocratização, e Agente de Desenvolvimento. Estes quatro pilares foram 
considerados durante o desenvolvimento do indicador como sendo fundamentais para garantir o apoio aos pequenos negócios locais.

O Agente de Desenvolvimento também está incluído na Lei Geral, sua atuação e perfil estão descritos na Lei Complementar $128 / 2008$, artigo 85 , por isso é um dos fatores considerados para implementação da Lei. Todos os itens inclusos na Lei podem ser base para o trabalho do agente. Nota-se o quão abrangente e multidisciplinar deve ser o perfil do agente de desenvolvimento, este é o tema do próximo capítulo.

\section{O Agente de Desenvolvimento: Perfil e Atuação}

O Agente de Desenvolvimento deve assumir o papel de responsável pela implementação das ações integradas ao processo de desenvolvimento do seu município. Sua articulação com o Poder Público, os lideres empresariais e da sociedade devem formar um arranjo articulado e operado pelo Agente de Desenvolvimento em prol dos municípios.

Quando o assunto é governança, o Agente é capaz de ampliar a capacidade de mobilização e influência sobre os recursos e instrumentos da gestão pública. De forma eficaz, esse ator poderá estender a diversos elos envoltos no desenvolvimento do município a participação no planejamento que passa a ser construído de forma conjunta e abrangente as diversas representações da sociedade .

A dinâmica de mudanças presente na sociedade atual, com o maior fluxo de informações, competitividade acirrada, aumento dos recursos de capital, bens, serviços, expondo todas as localidades a este novo contexto e condições econômicas. O fenômeno da globalização que envolve aspectos sociais, culturais, políticos e pessoais, recolocou, de maneira dramática, as relações entre sociedade e Estado, e eleva o número de interações entre os diversos entes locais e mundiais, desperta a discussão sobre os novos meios e padrões de articulação entre indivíduos, organizações, empresas e o próprio Estado, deixando clara a importância da governança em todos os níveis. Este contexto abre espaço para atuação de protagonistas regionais, que mobilizem os esforços, e reúnam interesses em prol do desenvolvimento municipal, esta é uma das vertentes de atuação do Agente (CNM/SEBRAE, 2011).

O perfil do Agente de Desenvolvimento é de um profissional com capacidade de planejamento, execução e articulação de políticas voltadas a implementação da Lei Geral da Microempresa e Empresa de Pequeno Porte, e voltadas ao benefício local. O Agente tem capacidade de negociação, equilibrando os diversos interesses atuantes no município e região. Outras habilidades que o Agente deve possuir incluem: solução de conflitos, planejamento estratégico, técnicas para moderação de grupos, elaboração e gestão de projetos, e captação de recursos (CNM/SEBRAE, 2011).

Ainda assim, o perfil e a atuação do Agente devem ser flexíveis a realidade e condições apresentadas no Município. Uma das principais fontes de inspiração ao trabalho do Agente é a Rede formada pelos agentes atuantes regionalmente, estadualmente e nacionalmente, que trocam experiências das ações que realizam em seus municípios e podem ser replicadas em outras localidades alcançando a resolução de problemas comuns.

É através da Rede e da flexibilidade apresentada nos municípios que o Agente empodera-se das atividades a serem executadas nos municípios, estruturadas em plano de ação, e aplica esforços, conhecimento e poder de articulação para Implementar a Lei Geral e utilizá-la como instrumento de desenvolvimento.

\section{Os Agentes de Desenvolvimento no Esta- do de Mato Grosso do Sul}

No Estado de Mato Grosso do Sul são 57 agentes nomeados pelas prefeituras municipais exercendo suas atividades em prol da Implementação da Lei Geral. O emprego desses agentes reflete o resultado exitoso de 26 municípios com a Lei Geral considerada como Implementada no Estado.

Em 45\% dos municípios do Estado que possuem Agente a Lei Geral pode ser considerada implantada em seus requisitos básicos, este dado apresenta a importância do trabalho do Agente. Nesta análise vale ressaltar que muitos destes agentes estaduais assumiram o cargo este ano devido ao pleito eleitoral 
de 2012 que conduziu mudanças no cenário político em todo o Estado, fator que acaba influenciando o planejamento dos Agentes.

Outro fato importante é que conforme mencionado anteriormente o Indicador de Implementação da Lei Geral passa a ser mensurado apenas no ano de 2012, os municípios que conseguiram atingir a nota básica para serem considerados com a Lei Implementada Inocência e Sonora, possuíam agentes desde 2011, ou seja, atuantes pelo desenvolvimento municipal em um período de um ano.

Em análise as notas dos municípios que possuem a Lei Implementada nota-se correlação positiva entre o critério Agente de Desenvolvimento e todos os outros critérios. Sendo que a relação entre o critério Agente de Desenvolvimento e Desburocratização é de $40 \%$, onde a existência de um Agente nomeado parece exercer forte influência sobre o processo de Desburocratização no procedimento de abertura de empresas no Estado.

No Estado de Mato Grosso do Sul, desde 2011, o Projeto de Apoio ao Desenvolvimento Econômico dos Municípios Fundamentado na Lei Geral das Microempresas e Empresas de Pequeno Porte - o PROLOCAL atende a 21 municípios e solicita como contrapartida, entre os critérios presentes desde o edital de seleção do projeto, a existência de um Agente de Desenvolvimento. Entre os 26 municípios com Lei Geral Implementada hoje no Estado, 17 são atendidos pelo PROLOCAL.

Outros 16 municípios com Lei Implementada estão em áreas contempladas pelo programa estadual Territórios da Cidadania, onde nas diretrizes dos projetos consta o estímulo a indicação de um Agente de Desenvolvimento. Os Territórios da Cidadania atuam no Estado desde o final do ano de 2011.

Os dados deixam claro a importância do Agente de Desenvolvimento para Implementação da Lei Geral no Estado de Mato Grosso do Sul. Não apenas por ser um dos critérios do indicador, mas pelo empenho individual destes para implantar a Lei e garantir os benefícios aos pequenos negócios instalados em seus municípios.

Vale citar que a Lei é apenas um dos instrumentos para promoção do desenvolvimento, e que os agentes envolvidos em rede e capacitados envolvem-se em diversas frentes. $\mathrm{O}$ investimento realizado para promoção do conhecimento da rede de Agentes é o legado que pode ser deixado aos municípios. São esses agentes os protagonistas locais de políticas e planos encaminhados regional e nacionalmente.

\section{Conclusão}

Através da Rede de Agentes de Desenvolvimento é possível fazer fluir conhecimento e discussão até as mais distantes localidades. O caso da implementação da Lei Geral certamente alcançará resultados superiores a partir do estabelecimento dos Agentes em seus cargos. Essa possibilidade de atuação replicada pode garantir a integração necessária às diversas regiões do Estado de Mato Grosso do Sul e do país. A governança estimulada por estes agentes que são os protagonistas pode ser multiplicada em diversos outros setores, replicand o o modelo e possibilitando benefícios a outros setores além dos pequenos negócios municipais.

Os Agentes envolvem-se localmente em diversos outros temas, e a rede de Agentes pode ser aproveitada nos municípios para promover a interação regional e local. Garantir capacitação a rede, e fomentar as discussões e encontros entre eles são formas de alimentar o trabalho realizado por esses protagonistas locais. A herança que os agentes constroem através da articulação e mobilização de esforços locais, regionais e estaduais pode apoiar o processo de desenvolvimento sustentável, em um ciclo de debates para que os recursos aplicados nos municípios possam ser eficientes e condizentes com os objetivos propostos.

A atuação em outras áreas além da Implementação da Lei Geral fica como sugestão a trabalhos futuros, que possam tentar dimensionar a prática do trabalho como Agente e suas alternativas para promoção do desenvolvimento sustentável.

\section{Referências}

BRASIL. Lei Complementar 123 de 14 de dezembro de 2006. Institui o Estatuto Nacional da Microempresa e da Empresa de Pequeno Porte; altera dispositivos das Leis n: 8.212 e 8.213 , ambas de 24 de julho de 1991, da Consolidação das Leis do Trabalho (CLT), aprovada pelo Decreto-Lei n. 5.452, de $1^{\circ}$ de maio de 1943 , da Lei n. 10.189, de 14 de fevereiro de 2001, da Lei Complementar n. 63, de 11 de janeiro de 1990; e revoga as 
Leis n. 9.317, de 5 de dezembro de 1996, e 9.841, de 5 de outubro de 1999. Disponível em: <http:/ / www.planalto.gov.br/ccivil_03/leis/lcp/lcp123.htm>. Acesso em: 01 out. 2013.

BRASIL. Lei Complementar 128 de 19 de dezembro de 2008. Altera a Lei Complementar $n^{\circ} 123$, de 14 de dezembro de 2006, altera as Leis n. 8.212, de 24 de julho de 1991, 8.213, de 24 de julho de 1991, 10.406, de 10 de janeiro de 2002 - Código Civil, 8.029, de 12 de abril de 1990, e dá outras providências. Disponível em: <http://www. receita.fazenda.gov.br/Legislacao/LeisComplementares/2008/leicp128.htm>. Acesso em: 20 abr. 2013.

BRASIL. Lei Complementar 139, de 10 de novembro de 2011. Altera dispositivos da Lei Complementar 123, de 14 de dezembro de 2006, e dá outras providências. Disponível em: <http:/ / www.receita.fazenda.gov.br/
Legislacao/LeisComplementares/2011/leicp139.htm>. Acesso em: 20 abr. 2013.

CONFEDERAÇÃO NACIONAL DOS MUNICÍPIOS (CNM); SERVIÇO BRASILEIRO DE APOIO ÀS MICRO E PEQUENAS EMPRESAS (SEBRAE). Manual de Desenvolvimento dos Municípios. Brasília, 2011, p. 67-78.

GONÇALVES, Alcindo. O Conceito de Governança. Disponível em: <http://conpedi.org.br/manaus/ arquivos/anais/XIVCongresso/078.pdf >. Acesso em: 01 out. 2013.

OBSERVATÓRIO DA LEI GERAL DA MICRO E PEQUENA EMPRESA. Lei Geral. Disponível em: < http:/ / www.leigeral.com.br/portal/ main.jsp?lumPageId= FF8081812658D379012665B59AB31CE5>. Acesso em: 01 out. 2013 